\title{
Management and prognosis of acute extracranial internal carotid artery occlusion
}

\author{
Lukas Mayer ${ }^{1}$, Astrid Grams ${ }^{2}$, Christian F. Freyschlag ${ }^{3}$, Maria Gummerer $^{4}$, Michael Knoflach ${ }^{1}$ \\ ${ }^{1}$ Department of Neurology, ${ }^{2}$ Department of Neuroradiology, ${ }^{3}$ Department of Neurosurgery, ${ }^{4}$ Department of Vascular Surgery, Medical University of \\ Innsbruck, Innsbruck, Austria \\ Contributions: (I) Conception and design: L Mayer, M Knoflach; (II) Administrative support: All authors; (III) Provision of study materials or patients: \\ None; (IV) Collection and assembly of data: All authors; (V) Data analysis and interpretation: All authors; (VI) Manuscript writing: All authors; (VII) \\ Final approval of manuscript: All authors. \\ Correspondence to: Michael Knoflach, MD. Department of Neurology, Medical University of Innsbruck, Anichstraße 35, Innsbruck 6020, Austria. \\ Email: Michael.Knoflach@i-med.ac.at.
}

\begin{abstract}
Acute occlusion of the internal carotid artery is the underlying etiology in 4 to $15 \%$ of all ischemic strokes. The clinical presentation varies considerably ranging from asymptomatic occlusion to severe ischemic strokes. Substantial differences in the acute management of acute symptomatic internal carotid artery occlusions (ICAO) exists between centers. Thusly, we comprised a narrative review of the natural course of acute ICAO and of available treatment options [i.v. thrombolysis, endovascular thrombectomy and stenting, bypass between the superficial temporal and the middle cerebral arteries (MCA) and carotid endarterectomy (CEA)]. We found that very few randomized treatment trials have been performed in patients acute symptomatic ICAO. Most evidence stems from case series and observational studies. Especially in older studies the intracranial vessel status has rarely been considered. After revision of these studies we concluded that the mainstay of the acute management of acute symptomatic ICAO is i.v. thrombolysis when applied within the label and in combination with mechanical thrombectomy in case of intracranial large vessel occlusion. In cases without intracranial large vessel occlusion mechanical thrombectomy of acute ICAO is associated with a risk of distal embolization. More research on prognostic parameters is needed to better characterize the risk of decompensation of collateral flow and to better define the time-window of intervention. When mechanical thrombectomy fails or is not available, surgical approaches are an alternative in selected patients.
\end{abstract}

Keywords: Carotid artery; internal; stroke; transient ischemic attacks (TIA)

Submitted Apr 06, 2020. Accepted for publication May 28, 2020.

doi: 10.21037/atm-20-3169

View this article at: http://dx.doi.org/10.21037/atm-20-3169

\section{Introduction}

Acute occlusion of the internal carotid artery occlusion (ICAO) is the underlying etiology for $4-15 \%$ of all ischemic strokes $(1,2)$ and mainly based on pre-existing atherosclerotic lesions evident in $53-55 \%$ of cases (3). Stenosis progression or plaque rupture with secondary thrombosis are believed to be the most common causes of acute ICAO $(3,4)$. Other etiologies like atrial fibrillation or arterial dissection have a considerably lower prevalence in these patients $(5,6)$. Clinically, acute ICAO can cause a variety of symptoms ranging from asymptomatic courses to transient ischemic symptoms or severe ischemic strokes (7). Lesion pattern, clinical presentation and risk of recurrent ischemic events are heavily dependent on occlusion sites. Factors like tandem occlusion of the ICA together with the middle cerebral (MCA) or anterior cerebral artery (ACA), insufficient collateral reserve for the occluded artery and systemic hemodynamic compromise, such as pre-existing cardiomyopathy and low blood pressure are associated with likelihood of ischemic stroke and worse outcomes 
(8-10). Annual recurrence rates of ischemic events in symptomatic acute ICAO reportedly lie between $10 \%$ and $18 \%$, with stump embolisms into downstream circulation being the most common cause (4). Additionally, in chronically occluded internal carotid arteries (i.e., without initial ischemic symptoms) the risk for ipsilateral TIA/ stroke is $5-7 \%$ per annum even under sufficient secondary prevention strategies $(9,11-13)$. Neurologically, patients with acute ICAO most frequently present with contralateral hemiparesis (4) while transient ischemic attacks (TIA) in the territory of the anterior circulation or retinal ischemia represent the most common ischemic symptoms in recurrence (14).

Acute ICAO frequently leads to severe ischemic strokes with an adverse functional outcome with $40-69 \%$ of patients showing residual severe neurological deficits and only $8-20.6 \%$ having a modified Rankin Scale (mRS) score $\leq 2(15-17)$ in follow-up as well as a high mortality of $16-55 \%$ (8). In cases of tandem MCA or ACA occlusion in addition to ICAO, outcomes are considered even more severe than in extra-cranial ICAO only (18). But as studies showed, fast recanalization of occluded arteries greatly improved clinical and functional outcome, which highlights the need for safe and effective treatment strategies in this subgroup of ischemic stroke patients $(6,19)$. This literature review focuses on current evidence concerning up to date acute treatment options in ischemic stroke patients with symptomatic acute ICAO.

\section{Approach: best medical-i.v. thrombolysis}

I.v. thrombolysis is known to be an effective treatment option for all acute ischemic stroke patients for two decades now, with an estimated risk of symptomatic thrombolysisassociated intracranial hemorrhage of about $5 \%$ when administered within the label (20-24). Yet, it is still unclear if the subgroup of patients with acute ICAO and ischemic stroke also benefit from this treatment. Clinical studies are scarce and to date only one randomized controlled trial compared i.v. thrombolysis against the natural course of acute ICAO patients. This trial [Echoplanar Imaging Thrombolytic Evaluation Trial (EPITHET)] even suggested that subjects receiving recombinant tissue plasminogen activator (rtPA) had worse functional outcomes than untreated patients (i.v. rtPA vs. natural course: $\mathrm{mRS} \leq 20 \%$ vs. $23.3 \% ; \mathrm{P}=0.257$ ) (25). This finding was supported by further case control series (i.e., ICARO studies) not showing a significant treatment effect on 3-month outcome (1,6,26-28). One major limitation of these early pre-thrombectomy trials, especially EPITHET, that i.v. rtPA was administered up to six hours after symptom onset (25). Even though most studies reported low recanalization rates $(4.4-12.5 \%)$ in general $(1,6,27,28)$, the probability was higher $(10 \%$ to $30 \%)$ if treatment was initiated within three hours of symptom onset (26), and considerably higher than in the natural course (8.6\%) (29). The fairly low recanalization rates can be explained by the fact that thrombolytic drugs are reliant on their delivery to and distribution within the blood clot in addition to the local pressure gradient adjacent to the clot (16) and the thrombus size (27).

The conclusions for clinical practice that can be drawn from all these studies is limited. In the few evaluations with information on the intracranial vessel status higher mortality rates and worse treatment effect of i.v. thrombolysis in patients having tandem occlusions compared to those with extra-cranial carotid artery occlusion only has been reported (30-32).

In summary, systemic i.v. thrombolysis seems to be a plausible but not highly effective treatment option in acute ICAO patients, which should not be withheld when used within the label.

\section{Approach: endovascular-thrombectomy and stenting}

Since the multiple positive randomized controlled trials of acute thrombectomy in patients with ischemic stroke due to large intracranial vessel occlusion of 2015 , intraarterial revascularization gained more and more momentum revealing indications and expanding time-to-treatmentwindows previously uncharted by medical treatment alone (33-37).

In the setting of ICAO in combination with intracranial large vessel occlusion (tandem occlusion), endovascular techniques are intriguing, and widely applied in clinical practice in those centers that have sufficient expertise and equipment to be readily available 24/7 (38). Studies, with rather small sample sizes (50-100 subjects), concluded that clinical outcomes in endovascular treatment of tandem pathologies are similar to those with endovascular therapy due to intracranial occlusion only (39-41).

Large uncertainties exist whether ICAO should be treated by aspiration and balloon angioplasty alone or in combination with acute stenting, and heterogeneity of approaches have been documented $(38,41)$. Arguments against acute ICA stenting are the (perceived) need for 
dual antiplatelet therapy that (probably) increases risk of intracerebral hemorrhage, especially in subjects with large infarct volume. Recent retrospective evaluations of the TITAN registry (thrombectomy in Tandem lesions) though hint that the use of antiplatelet therapy in this setting is save (42).

Two recent meta-analyses, including over 25 studies and more than 1,500 patients in total, revealed that time-torecanalization was significantly longer in subjects receiving stenting prior to thrombectomy compared to those with thrombectomy only, but clinical outcome characteristics such as favorable outcome $(50 \%$ vs. $53 \%)$, intracranial hemorrhage ( $8 \%$ vs. $7 \%)$ mortality $(16 \%$ vs. $14 \%)$ and recanalization rates $(80 \%$ vs. $75 \%)$ did not differ $(43,44)$. Consequently if available, stenting of upstream ICAO in tandem vessel occlusion seems to be a feasible option, but methodology differed in clinical application even on this level. A multi-center study of 165 patients compared an antegrade strategy (stenting prior to thrombectomy) to a retrograde strategy (thrombectomy prior to stenting). In this study, the retrograde method performed well with significantly higher rates of vessel reperfusion $(92 \% v s$. $56 \%$ ) and favorable outcomes ( $44 \%$ vs. $30 \%$ ) compared to those receiving stenting prior to thrombectomy (45). These results were replicated by smaller studies favoring the retrograde methodology $(46,47)$.

Only few studies focused on endovascular treatment in the setting of symptomatic isolated acute cervical ICAO (non-tandem pathology). One study of 22 patients found that recanalization could be achieved in $77 \%$ with following clinical improvement occurring in $46 \%$ of subjects and $50 \%$ having favorable clinical outcome 3 months after treatment (48). The authors highlighted that advanced age ( $>70$ years), failing of vessel recanalization, duration of vessel occlusion, presence of atrial fibrillation and pre-treatment NIHSS $>20$ were associated with worse clinical outcomes. Jadhav et al. (49) included 107 subjects with acute stenting of symptomatic ICAO achieving successful recanalization in $92 \%$, stabilization or improvement of NIHSS in $83 \%$ and favorable clinical outcome in $65 \%$ of cases. Interestingly, in this study median onset-to-treatment-time was 25 hours with still $93 \%$ of patients having perfusion-mismatch and $42 \%$ showing clinical-imaging mismatch, further highlighting the broadened time windows in endovascular treatment strategies in selected patients compared to medical treatment alone. Distal embolization of thrombotic material occurred in $22 \%$ requiring intra-arterial treatment in $17 \%$. One-year post-treatment, $15 \%$ of subjects had restenosis in stented cervical arteries with necessity of re- intervention.

Conclusively if available, thrombectomy is a feasible method with good rates of vessel recanalization and positive impact on patient outcome within 3 months after ischemic stroke in patients with acute ICAO. The additional effect of i.v. thrombolysis is proven in patients with tandem pathologies and should not be withheld in those with isolated extracranial acute ICAO. As no randomized controlled trials exist for the latter group, the current data on treatment effects stem from observational studies only. The clear benefit of a combined approach in isolated extracranial acute ICAO therefore is unknown but has to be weighed against a high risk of distal embolization in isolated extracranial acute ICAO.

\section{Approach: neurosurgery-STA-MCA bypass}

The first bypasses between the superficial temporal and the middle cerebral arteries (STA-MCA bypass) were performed in the late 60ies (50) in patients with ICA or MCA occlusions. Even though this technique was mainly used for subacute vessel occlusions followed by chronic cerebrovascular insufficiency, it has also been applied to the acute stroke setting. Whereas older studies report high mortality rates of $15 \%$ in acute cerebral bypass (51) more recent publications show high numbers of flow augmentation or flow preservation by extra-intracranial bypass surgery. Horiuchi et al. analyzed 59 patients with acute bypass surgery, showing significantly improved collateral flow and prevention of new infarction, with $1.6 \%$ deaths (due to myocardial infarction) and $16 \%$ morbidity (combined minor and major) (52). Several case series from the pre-thrombectomy era have been published, one included 7 patients with acute symptomatic ICAO (one with M2 occlusion where additional embolectomy was done) with a high DWI-ASPECT score [8-10] and a reduced cerebral blood flow in single-photon emission computed tomography. STA-MCA bypass was performed 1.5 to 23 (median 6) hours after symptom worsening and 7 to 112 (median 21) hours after symptom onset. Early neurological improvement at day 3 after surgery was observed in 3 patients (43\%) and 6 patients $(86 \%)$ had a good functional outcome (mRS $\leq 2) 6$ months later (53). Of 21 patients reported in a single center series that were ineligible for or had no successful recanalization by mechanical thrombectomy, 10 had a cervical ICAO that was inaccessible to carotid endarterectomy (CEA) and showed a small infarct core with a substantial perfusion mismatch. STA-MCA bypass was 
performed in 6 patients 5 to 9 hours after clinical worsening, in 3 patients 1 day and in 1 patient 7 days after stroke onset without subsequent worsening. In total, 70\% achieved good functional outcome ( $\mathrm{mRS} \leq 2)$ after 3 months (54).

STA-MCA bypass surgery has been regularly performed for decades in ICA atherosclerosis. However, three large randomized trials of bypass procedure in patients with subacute symptomatic high grade ICA or MCA atherosclerotic stenosis or occlusion (55) or subacute symptomatic ICA or MCA occlusion with hemodynamic cerebral ischemia defined by oxygen-extraction positron emission tomography (56) could not demonstrate a clinical benefit of bypass surgery. The COSS trial (56) showed comparable rates of ipsilateral stroke at 2 years in the surgical and medical group ( $21 \%$ vs. $22.7 \%, \mathrm{P}=0.78)$, however, the ipsilateral ischemic stroke rate after the second postoperative day was $9 \%$ in the surgical and $22.7 \%$ in the medical group (57). On the one hand medical therapy has improved mainly due to the introduction of statins, while the perioperative stroke rate was exceedingly high in COSS. Studies from large centers have reported 30-day stroke rates of less than 5\% (58-60) calling for specialized cerebrovascular centers $(61,62)$. Nevertheless, the failure of the bypass trials has nearly led to abandonment of this technique, although acute or subacute ICA or MCA occlusion, not amenable to medical or endovascular treatment may well benefit from rapid revascularization.

In summary, STA-MCA bypass surgery is not the first line therapy for acute extracranial ICAO and its rate has markedly declined over the last decades parallel with the advances of other available techniques. Case series of highly selected patients with symptomatic large vessel occlusion and subsequent neurological worsening, a small infarct core and a large perfusion deficit treated in specialized centers reported that bypass surgery was save. Early neurological improvement was reported in $46 \%$ (5 out of 11) patients and good functional outcome (mRS 2) was documented in $71 \%$ ( 15 out of 21 ) patients with a preoperative mean NIHSS of 13.1 (SD 4.7; median 12, range 5-24). These results differ little from an observational study of ICAO treated with i.v. and/or i.a. thrombolysis alone that reported a good functional outcome in 77\% (13 out of 17) patients with a mean NIHSS 11.4 (SD 4.2) (63). Yet, as the natural course of clinically instable patients with small infarct core and large perfusion mismatch might be less favorable, STAMCA bypass surgery should be seen as an option for very selected patients where medical or interventional therapy is not appropriate or has already failed.

\section{Approach: vascular surgery—endarterectomy}

CEA is well established in the treatment of symptomatic extra-cranial carotid artery stenosis (64). In this setting, urgent CEA is indicated, due to the considerable risk of early ischemic stroke recurrence, and a safe and effective treatment option if performed within 14 days after initial event (65-67).

The role of emergent surgical CEA in acute ICAO is limited, mostly due to the scarce evidence in the field. To date, no randomized controlled trial investigating the effectiveness and safety of acute CEA in ICAO patients exist, only case series which are mostly limited due to their small sample sizes $(60,68)$. A recent literature metaanalysis of 10 articles totalling 175 patients reported favourable outcome after acute surgical desobliteration of acute symptomatic ICAO with a high recanalization rate of $93 \%$ and mRS $0-2$ in short term follow-up of $62 \%$ and a low rate of peri- and postoperative complications such as intracerebral hemorrhage, early re-occlusion or in-hospital stroke (69). Still, emergent CEA did take a back seat in treatment consideration of acute symptomatic ICAO, especially due to expected perioperative risk of the more invasive method compared to intra-arterial recanalization procedures. When considering acute CEA patient selection seems essential. In 2008, a single centre series of 35 patients with acute symptomatic ICAO concluded that restoration of blood flow can only be achieved in the acute stage in $86 \%$ of cases with a moderate risk of neurological worsening or death (12\%). Patients were carefully selected by a thorough preoperative diagnostic work-up including diffusion- and perfusion weighted imaging to determine salvageable tissue (70). This pilot study was supported by later studies showing that in subjects with mismatch in perfusion imaging (60), recanalization rates (95-100\%) and functional outcome mRS $\leq 2$ in $40-80 \%$ after 3 months are favorable with mortality rates being similar to endovascular treatments $(15,68,71-76)$. A small case series of another promising group of patients with isolated ICAO looked at 6 subjects with moderate to severe strokes and compensated ipsilateral perfusion in CT perfusion imaging. Five of 6 patients responded well to acute CEA within the first hours after stroke onset (68). In this setting, demonstration of distal ICA patency is essential and technical success depends on the age of the thrombus (77).

CEA after recanalization (spontaneous, iv thrombolysis, mechanical thrombectomy) of ICAO with a residual highgrade stenosis is a viable treatment option in secondary stroke 
prevention 2 to 14 days after stroke (78-80). A recent study also highlighted that emergent CEA of a residual stenosis can be performed safely (75). Also, studies investigating CEA of asymptomatic stenosis contralateral to the acute ICAO have suggested beneficial outcomes due to collateral blood flow assistance reducing the risk of future stroke $(81,82)$.

In conclusion, the few articles focussing on surgical recanalization of acute ICAO suggest it to be a safe and a possible treatment option, however, critically dependent on patient selection.

\section{Conclusions}

When considering the acute management of extracranial ICAO, one has to differentiate between those with and without intracranial large vessel occlusion.

What we know from numerous endovascular thrombectomy trials is that early recanalization of the intracranial vessel occlusion is the most important parameter contributing to favorable outcome in ischemic stroke (33-37). Therefore, in patients with tandem pathologies a combined treatment of both the extracranial (with or without stenting) and intracranial occlusion through an endovascular (preferably retrograde) approach and i.v. thrombolysis is the standard therapy (38-41). As we know from the pre-thrombectomy-era, i.v. thrombolysis alone only has an uncertain and at best moderate effect on recanalization and outcome (1,6,26-28). Furthermore, i.v. thrombolysis is only an approved therapy option within the first 4.5 hours of ischemic symptom onset (label). In the rare event that intra-arterial procedures of the extracranially occluded ICA are not feasible or fail, surgical approaches such as CEA and bypass surgery are viable salvage therapy options. CEA is especially indicated if residual high-grade stenosis persists after initial extracranial angioplasty without stenting (78-80). The timing of CEA is dependent on infarct volume. Additionally, in the long run patients might benefit of CEA of a high grade contralateral carotid artery stenosis through assistance of collateral blood flow to the site of persistent ICAO $(81,82)$. STA-MCA bypass surgery is a save therapy if medical and interventional approaches are contraindicated or fail. Its safety though is reliant on proper patient selection and should be performed in centers with expertise in the field of vascular neurosurgery.

The best management of extracranial acute ICAO without subsequent intracranial large vessel occlusion is unclear because no randomized controlled trials exist. Consequently, therapeutic approaches differ substantially between centers. In general, i.v. thrombolysis is indicated in acute ischemic stroke irrespective of the extracranial vessel status and must not be withheld when applied within the label $(26,29)$. Endovascular revascularization of the acute ICAO comes with high risk of distal embolization (one fifth of cases) (49). Therefore, intervention should be restricted to subjects with minor neurological deficits and a high risk of clinical worsening or in those with substantial neurological deficits and a large penumbra. In both instances, collateral blood flow is on the verge of decompensation, yet parameters to estimate the risk for clinical worsening are ill-defined and have not been applied in larger cohorts. Clinically, low-flow TIAs like limb-shaking or retinal claudication (83) as well as dynamic neurological deficits induced by orthostatic maneuvers or by a drop in systemic blood pressure are indicative of insufficient collateralization. Cerebral blood flow can be measured by transcranial doppler ultrasound. A pseudovenous flow pattern or impaired flow-reserve in the breath holding (or $\mathrm{CO}_{2}$ inhalation) test indicating a maximal activated autoreserve in the MCA might serve as prognostic tool, yet has not been widely studied in this setting (84-86). Computed tomography or magnet resonance imaging perfusion imaging is well established to visualize the penumbra in ischemic stroke and has been successfully applied in randomized controlled thrombectomy trials $(87,88)$, yet a clear imaging definition of low-flow situations has yet to be established. Advanced functional imaging like ${ }^{123}$ I-IMP single-photon emission computed tomography with and without acetazolamide loading or $\mathrm{H}_{2}{ }^{15} \mathrm{O}$-Positron emission tomography imaging is rarely available in the acute stroke setting. Studies applying these imaging to select patients for STA/MCA bypass in the subacute stroke phase $(56,59)$ failed to show a benefit.

In Summary, the mainstay of the acute management of ICAO is i.v. thrombolysis when given within the label and mechanical thrombectomy if intracranial large vessel occlusion is present as well. There is a subgroup of instable patients with isolated acute ICAO that probably benefit from acute recanalization procedures. More research on prognostic parameters in this setting to better characterize the risk of clinical worsening and to better define the timewindow of intervention is needed.

\section{Acknowledgments}

Funding: This work is supported by VASCage-Research Center on Vascular Ageing and Stroke (Nr. 868624). As a 
COMET Center VASCage is funded within the COMET program - Competence Centers for Excellent Technologies by the Austrian Ministry for Climate Action, Environment, Energy, Mobility, Innovation and Technology, the Austrian Ministry for Digital and Economic Affairs and the federal states Tyrol, Salzburg and Vienna.

\section{Footnote}

Provenance and Peer Review: This article was commissioned by the Guest Editor (Dr. Kosmas I. Paraskevas) for the series "Carotid Artery Stenosis and Stroke: Prevention and Treatment Part I" published in Annals of Translational Medicine. The article was sent for external peer review organized by the Guest Editor and the editorial office.

Conflicts of Interest: All authors have completed the ICMJE uniform disclosure form (available at http://dx.doi. org/10.21037/atm-20-3169). The series "Carotid Artery Stenosis and Stroke: Prevention and Treatment Part I" was commissioned by the editorial office without any funding or sponsorship. The authors have no other conflicts of interest to declare.

Ethical Statement: The authors are accountable for all aspects of the work in ensuring that questions related to the accuracy or integrity of any part of the work are appropriately investigated and resolved.

Open Access Statement: This is an Open Access article distributed in accordance with the Creative Commons Attribution-NonCommercial-NoDerivs 4.0 International License (CC BY-NC-ND 4.0), which permits the noncommercial replication and distribution of the article with the strict proviso that no changes or edits are made and the original work is properly cited (including links to both the formal publication through the relevant DOI and the license). See: https://creativecommons.org/licenses/by-nc-nd/4.0/.

\section{References}

1. Rubiera M, Ribo M, Delgado-Mederos R, et al. Tandem internal carotid artery/middle cerebral artery occlusion: an independent predictor of poor outcome after systemic thrombolysis. Stroke 2006;37:2301-5.

2. Paciaroni M, Caso V, Venti M, et al. Outcome in patients with stroke associated with internal carotid artery occlusion. Cerebrovasc Dis 2005;20:108-13.
3. Leys D. Atherothrombosis: a major health burden. Cerebrovasc Dis 2001;11 Suppl 2:1-4.

4. Fisher M. Occlusion of the internal carotid artery. AMA Arch Neurol Psychiatry 1951;65:346-77.

5. Paciaroni M, Balucani C, Agnelli G, et al. Systemic thrombolysis in patients with acute ischemic stroke and Internal Carotid ARtery Occlusion: the ICARO study. Stroke 2012;43:125-30.

6. Paciaroni M, Inzitari D, Agnelli G, et al. Intravenous thrombolysis or endovascular therapy for acute ischemic stroke associated with cervical internal carotid artery occlusion: the ICARO-3 study. J Neurol 2015;262:459-68.

7. Faught WE, van Bemmelen PS, Mattos MA, et al. Presentation and natural history of internal carotid artery occlusion. J Vasc Surg 1993;18:512-23; discussion 524.

8. Buslovich S, Hines GL. Spontaneous recanalization of chronic internal carotid artery occlusions: report of 3 cases. Vasc Endovascular Surg 2011;45:93-7.

9. Powers WJ, Derdeyn CP, Fritsch SM, et al. Benign prognosis of never-symptomatic carotid occlusion. Neurology 2000;54:878-82.

10. Malhotra K, Goyal N, Tsivgoulis G. Internal Carotid Artery Occlusion: Pathophysiology, Diagnosis, and Management. Curr Atheroscler Rep 2017;19:41.

11. Persoon S, Klijn CJM, Algra A, et al. Bilateral carotid artery occlusion with transient or moderately disabling ischaemic stroke: clinical features and long-term outcome. J Neurol 2009;256:1728-35.

12. Persoon S, Luitse MJA, de Borst GJ, et al. Symptomatic internal carotid artery occlusion: a long-term follow-up study. J Neurol Neurosurg Psychiatry 2011;82:521-6.

13. Kao HL, Lin MS, Wang CS, et al. Feasibility of endovascular recanalization for symptomatic cervical internal carotid artery occlusion. J Am Coll Cardiol 2007;49:765-71.

14. North American Symptomatic Carotid Endarterectomy Trial Collaborators, Barnett HJ, Taylor DW, et al. Beneficial effect of carotid endarterectomy in symptomatic patients with high-grade carotid stenosis. N Engl J Med 1991;325:445-53.

15. Meyer FB, Sundt TM, Piepgras DG, et al. Emergency carotid endarterectomy for patients with acute carotid occlusion and profound neurological deficits. Ann Surg 1986;203:82-9.

16. Hernández-Pérez M, Pérez de la Ossa N, Aleu A, et al. Natural history of acute stroke due to occlusion of the middle cerebral artery and intracranial internal carotid artery. J Neuroimaging 2014;24:354-8. 
17. Paciaroni M, Agnelli G, Caso V, et al. Intravenous thrombolysis for acute ischemic stroke associated to extracranial internal carotid artery occlusion: the ICARO-2 study. Cerebrovasc Dis 2012;34:430-5.

18. Phan TG, Donnan GA, Srikanth V, et al. Heterogeneity in infarct patterns and clinical outcomes following internal carotid artery occlusion. Arch Neurol 2009;66:1523-8.

19. Bhatia R, Hill MD, Shobha N, et al. Low rates of acute recanalization with intravenous recombinant tissue plasminogen activator in ischemic stroke: real-world experience and a call for action. Stroke 2010;41:2254-8.

20. National Institute of Neurological Disorders and Stroke rt-PA Stroke Study Group. Tissue plasminogen activator for acute ischemic stroke. N Engl J Med 1995;333:1581-7.

21. Clark WM, Albers GW, Madden KP, et al. The rtPA (alteplase) 0- to 6-hour acute stroke trial, part A (A0276g): results of a double-blind, placebo-controlled, multicenter study. Thromblytic therapy in acute ischemic stroke study investigators. Stroke 2000;31:811-6.

22. Clark WM, Wissman S, Albers GW, et al. Recombinant tissue-type plasminogen activator (Alteplase) for ischemic stroke 3 to 5 hours after symptom onset. The ATLANTIS Study: a randomized controlled trial. Alteplase Thrombolysis for Acute Noninterventional Therapy in Ischemic Stroke. JAMA 1999;282:2019-26.

23. Matosevic B, Knoflach M, Werner P, et al. Fibrinogen degradation coagulopathy and bleeding complications after stroke thrombolysis. Neurology 2013;80:1216-24.

24. Tsivgoulis G, Kargiotis O, Rudolf J, et al. Intravenous thrombolysis for acute ischemic stroke in Greece: the Safe Implementation of Thrombolysis in Stroke registry 15-year experience. Ther Adv Neurol Disord 2018;11:1756286418783578.

25. De Silva DA, Brekenfeld C, Ebinger M, et al. The benefits of intravenous thrombolysis relate to the site of baseline arterial occlusion in the Echoplanar Imaging Thrombolytic Evaluation Trial (EPITHET). Stroke 2010;41:295-9.

26. Mori E, Yoneda Y, Tabuchi M, et al. Intravenous recombinant tissue plasminogen activator in acute carotid artery territory stroke. Neurology 1992;42:976-82.

27. Mokin M, Kass-Hout T, Kass-Hout O, et al. Intravenous thrombolysis and endovascular therapy for acute ischemic stroke with internal carotid artery occlusion: a systematic review of clinical outcomes. Stroke 2012;43:2362-8.

28. Yeo LLL, Kong WY, Paliwal P, et al. Intravenous Thrombolysis for Acute Ischemic Stroke due to Cervical Internal Carotid Artery Occlusion. J Stroke Cerebrovasc Dis 2016;25:2423-9.
29. Pechlaner R, Knoflach M, Matosevic B, et al. Recanalization of extracranial internal carotid artery occlusion after i.v. thrombolysis for acute ischemic stroke. PLoS One 2013;8:e55318.

30. Gliem M, Lee JI, Barckhan A, et al. Outcome and Treatment Effects in Stroke Associated with Acute Cervical ICA Occlusion. PLoS One 2017;12:e0170247.

31. Endo S, Kuwayama N, Hirashima Y, et al. Results of urgent thrombolysis in patients with major stroke and atherothrombotic occlusion of the cervical internal carotid artery. AJNR Am J Neuroradiol 1998;19:1169-75.

32. Zaidat OO, Suarez JI, Santillan C, et al. Response to intra-arterial and combined intravenous and intra-arterial thrombolytic therapy in patients with distal internal carotid artery occlusion. Stroke 2002;33:1821-6.

33. Jovin TG, Chamorro A, Cobo E, et al. Thrombectomy within 8 hours after symptom onset in ischemic stroke. N Engl J Med 2015;372:2296-306.

34. Goyal M, Demchuk AM, Menon BK, et al. Randomized assessment of rapid endovascular treatment of ischemic stroke. N Engl J Med 2015;372:1019-30.

35. Campbell BCV, Mitchell PJ, Kleinig TJ, et al. Endovascular therapy for ischemic stroke with perfusionimaging selection. N Engl J Med 2015;372:1009-18.

36. Saver JL, Goyal M, Bonafe A, et al. Stent-retriever thrombectomy after intravenous t-PA vs. t-PA alone in stroke. N Engl J Med 2015;372:2285-95.

37. Berkhemer OA, Fransen PSS, Beumer D, et al. A randomized trial of intraarterial treatment for acute ischemic stroke. N Engl J Med 2015;372:11-20.

38. Jacquin G, Poppe AY, Labrie M, et al. Lack of Consensus Among Stroke Experts on the Optimal Management of Patients With Acute Tandem Occlusion. Stroke 2019;50:1254-6.

39. Grigoryan M, Haussen DC, Hassan AE, et al. Endovascular Treatment of Acute Ischemic Stroke Due to Tandem Occlusions: Large Multicenter Series and Systematic Review. Cerebrovasc Dis 2016;41:306-12.

40. Fahed R, Redjem H, Blanc R, et al. Endovascular Management of Acute Ischemic Strokes with Tandem Occlusions. Cerebrovasc Dis 2016;41:298-305.

41. Assis Z, Menon BK, Goyal M, et al. Acute ischemic stroke with tandem lesions: technical endovascular management and clinical outcomes from the ESCAPE trial. J Neurointerv Surg 2018;10:429-33.

42. Zhu F, Anadani M, Labreuche J, et al. Impact of Antiplatelet Therapy During Endovascular Therapy for Tandem Occlusions: A Collaborative Pooled Analysis. 
Stroke 2020;51:1522-9.

43. Pires Coelho A, Lobo M, Gouveia R, et al. Overview of evidence on emergency carotid stenting in patients with acute ischemic stroke due to tandem occlusions: a systematic review and meta-analysis. J Cardiovasc Surg (Torino) 2019;60:693-702.

44. Sadeh-Gonik U, Tau N, Friehmann T, et al. Thrombectomy outcomes for acute stroke patients with anterior circulation tandem lesions: a clinical registry and an update of a systematic review with meta-analysis. Eur J Neurol 2018;25:693-700.

45. Maus V, Borggrefe J, Behme D, et al. Order of Treatment Matters in Ischemic Stroke: Mechanical Thrombectomy First, Then Carotid Artery Stenting for Tandem Lesions of the Anterior Circulation. Cerebrovasc Dis 2018;46:59-65.

46. Lockau H, Liebig T, Henning T, et al. Mechanical thrombectomy in tandem occlusion: procedural considerations and clinical results. Neuroradiology 2015;57:589-98.

47. Rangel-Castilla L, Rajah GB, Shakir HJ, et al. Management of acute ischemic stroke due to tandem occlusion: should endovascular recanalization of the extracranial or intracranial occlusive lesion be done first? Neurosurg Focus 2017;42:E16.

48. Hauck EF, Natarajan SK, Ohta H, et al. Emergent endovascular recanalization for cervical internal carotid artery occlusion in patients presenting with acute stroke. Neurosurgery 2011;69:899-907; discussion 907.

49. Jadhav A, Panczykowski D, Jumaa M, et al. Angioplasty and stenting for symptomatic extracranial non-tandem internal carotid artery occlusion. J Neurointerv Surg 2018;10:1155-60.

50. Yasargil MG, Krayenbuhl HA, Jacobson JH. Microneurosurgical arterial reconstruction. Surgery 1970;67:221-33.

51. Crowell RM. Emergency cerebral revascularization. Clin Neurosurg 1986;33:281-305.

52. Horiuchi T, Nitta J, Ishizaka S, et al. Emergency EC-IC bypass for symptomatic atherosclerotic ischemic stroke. Neurosurg Rev 2013;36:559-64; discussion 564-5.

53. Sugiyama T, Kazumata K, Asaoka K, et al. Reappraisal of Microsurgical Revascularization for Anterior Circulation Ischemia in Patients with Progressive Stroke. World Neurosurg 2015;84:1579-88.

54. Park HS, Kim SH, Nah HW, et al. Patient Selection and Clinical Efficacy of Urgent Superficial Temporal ArteryMiddle Cerebral Artery Bypass in Acute Ischemic Stroke
Using Advanced Magnetic Resonance Imaging Techniques. Oper Neurosurg (Hagerstown) 2017;13:552-9.

55. EC/IC Bypass Study Group. Failure of extracranialintracranial arterial bypass to reduce the risk of ischemic stroke. Results of an international randomized trial. N Engl J Med 1985;313:1191-200.

56. Powers WJ, Clarke WR, Grubb RL, et al. Extracranialintracranial bypass surgery for stroke prevention in hemodynamic cerebral ischemia: the Carotid Occlusion Surgery Study randomized trial. JAMA 2011;306:1983-92.

57. Grubb RL, Powers WJ, Clarke WR, et al. Surgical results of the Carotid Occlusion Surgery Study. J Neurosurg 2013;118:25-33.

58. Hayden MG, Lee M, Guzman R, et al. The evolution of cerebral revascularization surgery. Neurosurg Focus 2009;26:E17.

59. Ogasawara K, Ogawa A. JET study (Japanese EC-IC Bypass Trial). Nippon Rinsho 2006;64 Suppl 7:524-7.

60. Schubert J, Witte OW, Settmacher U, et al. Acute Stroke Treatment by Surgical Recanalization of Extracranial Internal Carotid Artery Occlusion: A Single Center Experience. Vasc Endovascular Surg 2019;53:21-7.

61. Esposito G, Amin-Hanjani S, Regli L. Role of and Indications for Bypass Surgery After Carotid Occlusion Surgery Study (COSS)? Stroke 2016;47:282-90.

62. Hänggi D, Steiger HJ, Vajkoczy P. The Role of MCA-STA Bypass Surgery After COSS and JET: The European Point of View. Acta Neurochir Suppl 2014;119:77-8.

63. Hong JM, Lee SE, Lee S-J, et al. Distinctive patterns on CT angiography characterize acute internal carotid artery occlusion subtypes. Medicine (Baltimore) 2017;96:e5722.

64. Rothwell PM, Eliasziw M, Gutnikov SA, et al, Carotid Endarterectomy Trialists Collaboration. Endarterectomy for symptomatic carotid stenosis in relation to clinical subgroups and timing of surgery. Lancet 2004;363:915-24.

65. Johansson EP, Arnerlöv C, Wester P. Risk of recurrent stroke before carotid endarterectomy: the ANSYSCAP study. Int J Stroke 2013;8:220-7.

66. Sharpe R, Sayers RD, London NJM, et al. Procedural risk following carotid endarterectomy in the hyperacute period after onset of symptoms. Eur J Vasc Endovasc Surg 2013;46:519-24.

67. Rantner B, Schmidauer C, Knoflach M, et al. Very urgent carotid endarterectomy does not increase the procedural risk. Eur J Vasc Endovasc Surg 2015;49:129-36.

68. Gunka I, Krajickova D, Lesko M, et al. Emergent Carotid Thromboendarterectomy for Acute Symptomatic Occlusion of the Extracranial Internal Carotid Artery. Vasc 
Endovascular Surg 2017;51:176-82.

69. Beneš V, Bradáč O, Horváth D, et al. Surgery of acute occlusion of the extracranial internal carotid artery - a meta-analysis. VASA 2020;49:6-16.

70. Weis-Müller BT, Huber R, Spivak-Dats A, et al. Symptomatic acute occlusion of the internal carotid artery: reappraisal of urgent vascular reconstruction based on current stroke imaging. J Vasc Surg 2008;47:752-9; discussion 759.

71. Berthet JP, Marty-Ané CH, Picard E, et al. Acute carotid artery thrombosis: description of 12 surgically treated cases. Ann Vasc Surg 2005;19:11-8.

72. Kasper GC, Wladis AR, Lohr JM, et al. Carotid thromboendarterectomy for recent total occlusion of the internal carotid artery. J Vasc Surg 2001;33:242-9; discussion 249-50.

73. Jiao L, Song G, Hua Y, et al. Recanalization of extracranial internal carotid artery occlusion: A 12-year retrospective study. Neural Regen Res 2013;8:2204-6.

74. Kiyofuji S, Inoue T, Tamura A, et al. Emergent cervical surgical embolectomy for extracranial internal carotid artery occlusion. Acta Neurochir (Wien) 2015;157:1313-8; discussion 1318-9.

75. Slawski DE, Jumaa MA, Salahuddin H, et al. Emergent carotid endarterectomy versus stenting in acute stroke patients with tandem occlusion. J Vasc Surg 2018;68:1047-53.

76. Kappelhof M, Marquering HA, Berkhemer OA, et al. Intra-arterial treatment of patients with acute ischemic stroke and internal carotid artery occlusion: a literature review. J Neurointerv Surg 2015;7:8-15.

77. Cho YP, Kwon TW, Kwon SU, et al. Carotid endarterectomy for symptomatic complete occlusion of the internal carotid artery. Acta Med Okayama 2011;65:239-45.

Cite this article as: Mayer L, Grams A, Freyschlag CF, Gummerer M, Knoflach M. Management and prognosis of acute extracranial internal carotid artery occlusion. Ann Transl Med 2020;8(19):1268. doi: 10.21037/atm-20-3169
78. Koraen-Smith L, Troëng T, Björck M, et al, Swedish Vascular Registry and the Riks-Stroke Collaboration. Urgent carotid surgery and stenting may be safe after systemic thrombolysis for stroke. Stroke 2014;45:776-80.

79. Naylor AR. Thrombolysis and expedited carotid revascularization. J Cardiovasc Surg (Torino) 2015;56:159-64.

80. Luitse MJA, Velthuis BK, Dauwan M, et al. Residual highgrade stenosis after recanalization of extracranial carotid occlusion in acute ischemic stroke. Stroke 2015;46:12-5.

81. Issawi A, Klopfenstein J. Can a closed carotid artery be reopened? Curr Cardiol Rep 2015;17:85.

82. Friedman SG, Lamparello PJ, Riles TS, et al. Surgical management of the patient with bilateral internal carotid artery occlusion. J Vasc Surg 1987;5:715-8.

83. Kiechl S, Furtner M, Knoflach M, et al. Kaleidoscopic vision and a jerking leg on the ski slope. Lancet 2007;370:1878.

84. Naqvi J, Yap KH, Ahmad G, et al. Transcranial Doppler ultrasound: a review of the physical principles and major applications in critical care. Int J Vasc Med 2013;2013:629378.

85. Saqqur M, Khan K, Derksen C, et al. Transcranial Doppler and Transcranial Color Duplex in Defining Collateral Cerebral Blood Flow. J Neuroimaging 2018;28:455-76.

86. Castro P, Azevedo E, Sorond F. Cerebral Autoregulation in Stroke. Curr Atheroscler Rep 2018;20:37.

87. Albers GW, Marks MP, Kemp S, et al. Thrombectomy for Stroke at 6 to 16 Hours with Selection by Perfusion Imaging. N Engl J Med 2018;378:708-18.

88. Nogueira RG, Jadhav AP, Haussen DC, et al. Thrombectomy 6 to 24 Hours after Stroke with a Mismatch between Deficit and Infarct. N Engl J Med 2018;378:11-21. 